\title{
School education for disaster risk reduction in Japan after the 2011 Great East Japan Earthquake and Tsunami (GEGET)
}

\author{
T. FüIOKA ${ }^{1}$, Y. SAKaKkBARA ${ }^{2}$ \\ 1 - Faculty of Education, Shiga University, 520-0862 Hiradu 0tsu, Shiga, Japan. E-mall: fujoka@edu.shiga-U.ac.jp \\ 2 - Facuty of Education, Shinshu University 380-8544 Nagano city, Nagano, Japan. E-mall: ysakaki@Shinshu-U.ac.Jp
}

Abstract: The 2011 Great East Japan Earthquake and Tsunami (GEJET), reminded us Japanese of the harsh realities of the natural environment in the Japanese Archipelago and the importance of crisis management systems. However, the treatment of disasters has not been neglected in Japan, where natural disasters have historically occurred. In Japan, here are two separate approaches to handling natural disasters in formal education. The first is learning within specific subject areas, particularly social studies and science. The second is educational activities that take place outside subject teaching hours. Although natural disasters are common in the Japanese Archipelago, this arc-shaped string of islands, surrounded by the ocean and possessing a rich natural landscape, has greatly influenced Japanese culture, science and technology, and education. The Pacific Ocean coastline of the Tohoku region has been frequently hit in recent years by large killer waves (Tsunami) that have repeatedly resulted in serious damage. The main difference between the 2011 GEJET, and the previous tsunamis that hit the region is the accident that occurred at the Fukushima I Nuclear Power Plant. Because the perspective of understanding science and technology from a social context is closely related to issues in education today.

\section{Manuscript:}

Received: Quadrennial Conference of the International Geoscience Education Organization Accepted:10/08/2018

Citation:Fujioka T., Sakakibara Y.. 2018. School education for disaster risk reduction in Japan after the 2011 Great Japan Earthquake and Tsunami (GEGET). Terræ Didatica, 14(3):313-319. URL: http://www.ige.unicamp.br/terraedidatica/.

Keywords: GEJET, ESD, Education for Disaster Risk Reduction, School Education in Japan

Thematic line: Environmental Education, Education for Sustainability and Geoethics.

\section{Introduction}

Many natural disasters have occurred in Japan. Therefore, the educational administration has also responded in various ways. Recently, following the 1995 Great Hanshin-Awaji Earthquake, the Ministry of Education, Culture, Sports, Science and Technology (MEXT) re-examined school disaster safety, produced supplementary materials on natural disasters and disaster prevention education, and conducted teacher training courses focusing on the affected areas in the Hanshin region. Between the 1995 Great Hanshin-Awaji Earthquake and the 2011 GEJET, there were seven earthquakes named by the Japan Meteorological Agency, including the 2004 Chuetsu Earthquake and the 2007 Chuetsuoki Earthquake. When a large-scale natural disaster occurs in Japan, a name is assigned to that disaster with the expectation that valuable lessons and experiences learned from it will be passed down to future generations and that relevant bodies will smoothly conduct emergency response and reconstruction activities after the disaster. Furthermore, a large number of weather-related disasters named by the Japan Meteorological Agency have occurred, such as the torrential rains in Niigata and Fukushima in 2004 and 2011, and rain events in northern Kyushu in 2012 and 2017. In 2014, the Cabinet Office Central Disaster Prevention Council set up a working group on landslide damage following the landslides that occurred in Hiroshima Prefecture that year and the frequent occurrence of landslides in other vulnerable areas. The working group reported its findings the following year, pointing out the importance of disaster prevention training in schools as well as in traditional areas.

There are two separate approaches to handling natural disasters in formal education in Japan. The first is learning within specific subject areas, particularly social studies and science that deals with the formation of the natural landscape, causes of natural disasters, and the effects of natural disasters on people. The second is educational activities that take place outside subject teaching hours, such as disaster drills and the creation of manuals for dis-

\begin{tabular}{c|c|c|c|c|c}
\hline (C) Terrae Didat. & Campinas, SP & v.14 & n.3 & $313-319$ & jul./set. 2018 \\
\hline
\end{tabular}


aster prevention. Regarding the former approach, despite the need for a cross-curricular approach, the topic of natural disasters is still dealt with in the confines of individual subject areas. That is, the natural environment and the social environment are covered separately in science education and social studies education, respectively. Because of the different goals and characteristics of these two subject areas, natural disasters have not been comprehensively covered. On the other hand, activities outside of formal teaching have placed a greater emphasis on hands-on activities than on the scientific understanding of the causes of natural disasters. For example, there has been a tendency to concentrate more on what to do during and after a natural disaster through, for example, lifesaving techniques and evacuation training. Because of differences among the departments responsible for these activities, from the Ministry of Education to the boards of education in Japan's administrative districts, each of these activities is independently treated. Accordingly, it is hard to say that they are linked. In this paper, these problems are specifically considered in an investigation of the school curricula.

Based on a discussion of the challenges faced by the education in Japan at different periods, this paper examines the overall ways that disaster prevention education related to natural disasters in school education has changed and the developments that will be necessary in the future.

\section{Urgent Issues in School Disaster Safety and Education for Disaster Risk Reduction to the Present}

The Pacific Ocean coastline of the Tohoku region has been frequently hit in recent years by large killer waves (Tsunami) that have repeatedly resulted in serious damage. The main difference between the 2011 GEJET, and the previous tsunamis that hit the region is the accident that occurred at the Fukushima I Nuclear Power Plant (Fujioka 2011). Because the perspective of understanding science and technology from a social context is closely related to issues in education today, these themes are touched on in this paper.

Following the 2008 and 2009 revisions to the school curricular guidelines, science education in Japan was divided into the four domains of physics, chemistry, biology, and earth sciences to provide continuity from elementary school to senior high

Table 1. Number of science textbooks in Japanese high-school

\begin{tabular}{l|l|l}
\hline \multicolumn{1}{c|}{ Subject } & $\begin{array}{l}\text { Number of } \\
\text { textbooks }\end{array}$ & $\begin{array}{l}\text { Selection } \\
\text { rate (\%) }\end{array}$ \\
\hline $\begin{array}{l}\text { Science and human } \\
\text { life }\end{array}$ & 428,312 & 9.5 \\
\hline Basic physics & 735,868 & 16.4 \\
\hline Basic chemistry & $1,030,895$ & 22.9 \\
\hline Basic biology & $1,085,117$ & 24.1 \\
\hline Basic earth sciences & 316,600 & 7.0 \\
\hline Physics & 235,510 & 5.2 \\
\hline Chemistry & 347,361 & 7.7 \\
\hline Biology & 303,137 & 6.7 \\
\hline Earth sciences & 16,350 & 0.4 \\
\hline Total & $4,499,150$ & 100.0 \\
\hline
\end{tabular}

school. It can be argued that some improvements resulted from the revisions to the compulsory high school subject of science in the current school curricular guidelines. However, enrollment in high school earth sciences remains low compared to the other three domains. Moreover, the number of examinees taking the university entrance examinations in earth sciences offered by the National Center for University Admissions is low. Table shows the rates of adoption of high school science textbooks in the 2014 school year.

In 1998, in the wake of the 1995 Great Hanshin-Awaji Earthquake, which claimed more than 6,000 lives and was Japan's worst earthquake disaster in the postwar period, revised curricular guidelines were announced. Reflecting the influence of the earthquake, the guidelines included a significant focus on natural disasters in the content of each subject, particularly science and social studies. Furthermore, these guidelines contained the first mention of fostering a "the zest for living" in education.

This idea relates to providing a balanced education comprised of the three pillars of knowledge, morality, and physical strength to create healthy, well-rounded individuals with sound academic abilities and moral values who function well in a changing society. Since these revisions to the curricular guidelines, "periods for integrated study" have been incorporated into the curricula from elementary through high school (Fujioka 2006).

After the 1995 Great Hanshin-Awaji Earthquake (Fig. 1), supplementary teaching materials covering the disaster were produced by the boards of education of two of the affected areas: Kobe City and Hyogo Prefecture. These teaching materials were used mostly in the periods for integrated study mentioned above. The environment, \begin{tabular}{|l|l|l|l} 
v.14 & n.3 & $313-319$ & jul./set. 2018 \\
\hline
\end{tabular} 


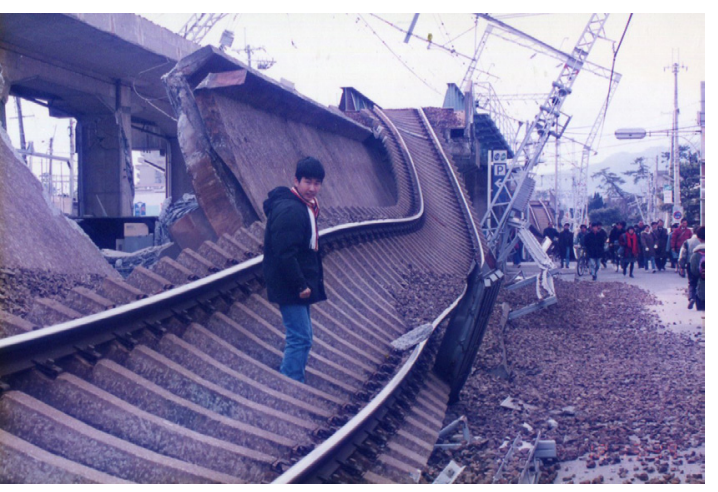

Figure 1. Damage of the 1995 Great Hanshin-Awaji Earthquake

international understanding, ICT, and health and welfare are examples of the content in integrated study periods. However, no specific mention is made in these materials of topics such as safety or disaster prevention. Nevertheless, it is clear that disaster prevention is not unrelated to the content listed in the examples.

\section{Formal Education and the School Curricula in Japan after the Great East Japan Earthquake}

The 2011 GEJET inflicted enormous damage on school children, school staffs, and facilities. More than 600 students and school staff died in the disaster. All of these losses resulted from the tsunami that followed the earthquake. Thanks in part to the improvements made to earthquake-resistant construction since the Great Hanshin-Awaji Earthquake, there were no confirmed deaths of students resulting from the collapse of school buildings.

Following the 2011 GEJET, MEXT quickly convened a committee of experts to determine the lessons to be learned from the earthquake in terms of disaster education and crisis management. The committee published an interim report in September of that year and released its final report in July of the next year. Based on its discussions, the committee made recommendations for disaster education that would be appropriate for the stage of development students had reached after a disaster. These recommendations were published in March of 2013 as a school disaster-prevention reference material, entitled "The zest for living: Disaster Prevention Education," which was distributed to every school in the country. In addition, one year after the 2011 GEJET, MEXT(2012) published "A Guide to Compiling School Disaster Preven- tion Manuals (Earthquakes/Tsunami)" which led schools across the country to review their existing disaster prevention manuals (Fig. 2).

Subsequently, each administrative division of Japan received support through MEXTs "Practical Disaster Prevention Education Support Project", conducted numerous teacher training courses, and addressed issues in supplementary readers on disaster education. However, the issue of school safety had been raised before the 2011 GEJET. The School Health and Safety Act had been in force since April of 2009, and there had been demand for the enhancement of school safety through the formulation of a comprehensive school safety plan. The factors behind this demand included the school invasion and massacre at Ikeda Elementary School (an elementary school affiliated with Osaka Kyoiku University), accidents in which students fell from school buildings, and traffic accidents outside schools. These incidents led to calls for an urgent response regarding daily safety (including crime prevention), road safety, and disaster safety (synonymous with disaster prevention). During the disasters mentioned above (the Great HanshinAwaji Earthquake of 1995, the subsequent Chuetsu Earthquake in 2004, the Chuetsu-oki Earthquake in 2007, and torrential rain in Niigata and Fuku-

落ちてこない・倒れてこない・移動してこない場所に。
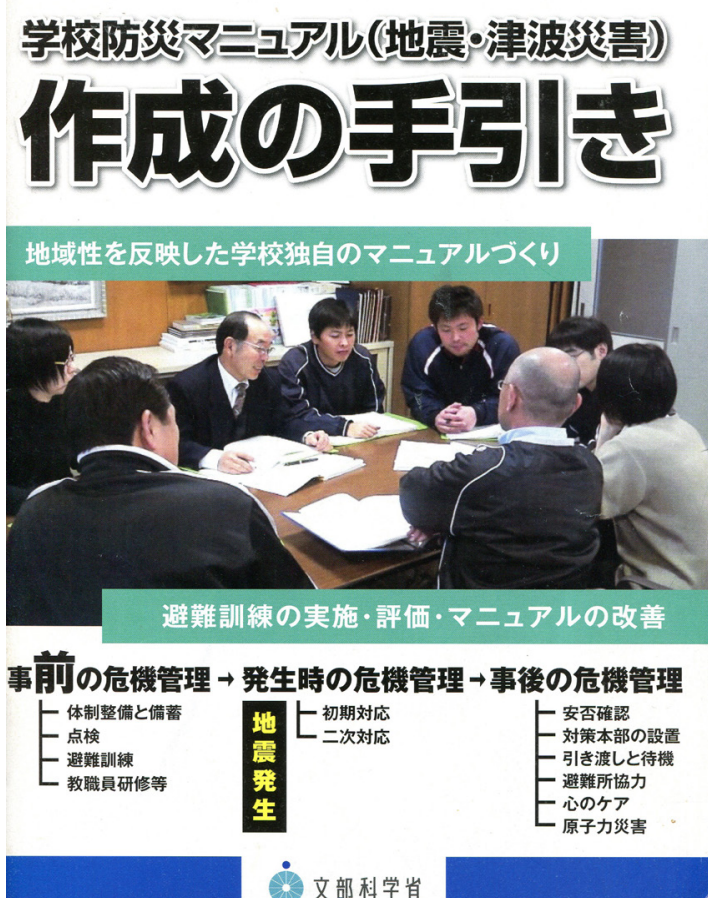

Figure 2. "A Guide to Compiling School Disaster Prevention Manuals (Earthquakes/Tsunami)"

\begin{tabular}{c|c|c|c|c|c}
\hline (C) Terrae Didat. & Campinas, SP & v.14 & n.3 & $313-319$ & jul./set. 2018 \\
\hline
\end{tabular}


shima in 2004), schools were used as refuges, and teachers were compelled to provide support based on their experiences as the schools moved toward post-disaster reopening. A great deal of energy and financial resources were consistently invested in flood prevention projects in the postwar period in response to the frequent flooding of rivers and flood damage caused by torrential rains and typhoons. Therefore, flood damage has declined, and the flood control measures are considered a success.

Nevertheless, coverage of alluvial materials has been reduced in each revision of the national curricula since the postwar period. There also is some indication that there has been a decline in the number of questions on flood damage in international assessments (Fujioka 1999). Based on these experiences, the need to try to improve school safety regarding a variety of natural disasters was recognized, after the 2011 GEJET (Fig. 3).

\section{Japan's Educational Reform and the Cultivation of "The zest for living"}

Some scholars have argued that educational reform in Japan up to this point resulted from strong influences in the international community (external pressures). Indeed, this seems undeniable with respect to the Meiji educational system and the first and second educational reforms that occurred under postwar democracy. It also seems possible that the stimulus for the third educational reform came from abroad. For example, the results of international assessments, such as the Trends in International Mathematics and Science Study (TIMSS) and the OECD Programme for International Student Assessment (PISA), are reflected in subsequent curricular guidelines, and their influence on the educational world in Japan is difficult to ignore. In addition, the importance of education providing a response to external pressures, such as those resulting from the Trans-Pacific Partnership (TPP), is often pointed out in the business community.

At this point, in addition to the motivating factors of the external community, internal pressures are considered in terms of the nation's response to major earthquake disasters. As previously explained, the term, "the zest for living," first appeared in the 1998 curricular guidelines following the 1995 Great Hanshin-Awaji Earthquake. In

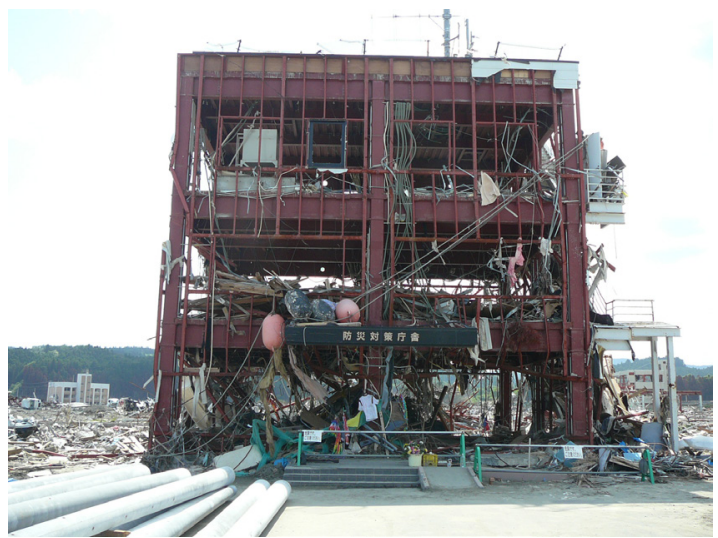

Figure 3. Damaged Buildind by the 2011 GEJET

that year, MEXT published "The zest for living: Disaster Prevention Education." A revised version was issued in March of 2013 and distributed to every school.

Unlike the first and second educational reforms, the third educational reform did not rely on a model or template from other countries. In the past, the goal was to create an educational system that enabled students to efficiently acquire skills and knowledge in fields, such as science and technology, in which the West had advanced beyond Japan. Now, however, something different was required of Japan's educational system and there was confusion among the schools and the teachers about exactly what to teach in the future and how to teach it.

The cultivation of a "the zest for living," which is emphasized in education in Japan today, comprises relationships with nature; science, technology and energy; the environment; and the international community, areas to which education will

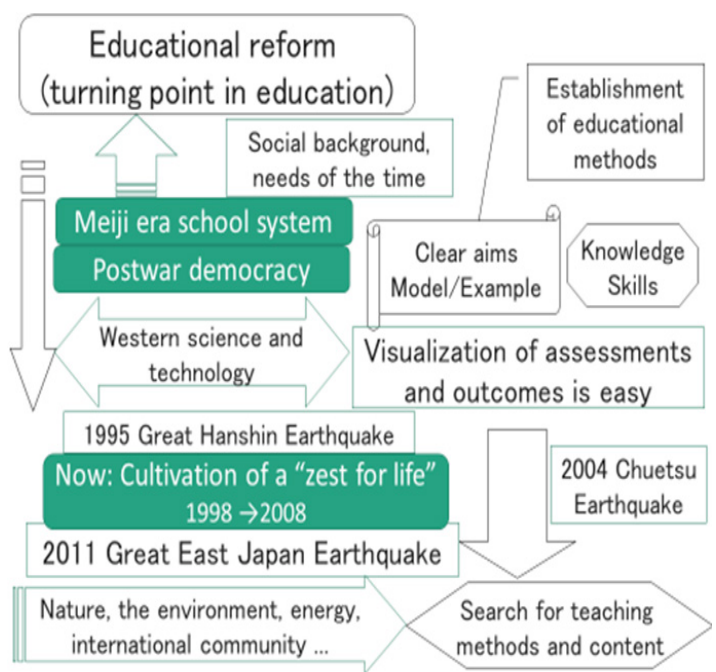

Figure 4. The cultivation of a "the zest for living," 
be required to respond in the near future (Fig. 4).

In response to the large-scale damage caused by the Great East Japan Earthquake disaster, including the earthquake, the tsunami, and the radiation, educators in Fukushima Prefecture grappled with reconstruction education, disaster prevention education, and even radiation education. These efforts represent a method that embodies expectations for education aimed at fostering a "the zest for living" (Fukushima Prefecture Board of Education 2014).

\section{Challenges Facing Disaster-prevention Education in Japanese Education}

At present and since the accident at the Fukushima I Nuclear Power Plant that followed the 2011 GEJET, we should consider once again the relationships among science, technology, and society (Fujioka 2015). This is significant, particularly in Japan, where conservation education and pollution education are included in environmental education.

Since 1990, there has been an emphasis on environmental education in the Japanese curricula. Internationally, environmental education and Education for Sustainable Development (ESD) came to be understood as equivalent to each other after the Thessaloniki Conference of 1997. However, in Japan, the idea that environmental education should emphasize environmental protection continued. Although some teaching materials on environmental education published by MEXT since the 1990s were revised in 2007 and 2014 to reflect the ESD perspective, these revisions were limited to materials for elementary schools. Teaching materials for junior and high schools have not yet been revised. The difficulty of implementing environmental education in secondary schools in Japan underlies this distinction.

The necessity to reflect once again on the development of scientific literacy was brought home following the accident at Fukushima I Power Plant caused by the Great East Japan Earthquake. As Torahiko Terada (1934) stated in his work, Natural Disaster and National Defence, "The more civilization advances, the greater the devastation which nature's tyranny brings about." The history of earthquakes and tsunamis in the Tohoku region bears out this statement. For instance, both the 1896 and 1933 Sanriku earthquakes and tsunamis caused enormous damage to the region. However, the tsunami resulting from the Great East Japan
Earthquake caused never before seen damage in the form of the Fukushima nuclear power plant accident.

Developments in science and technology, and expectations for more such developments, undoubtedly have a profound influence on the development of society and people's demands.

To move toward solutions to future problems of disaster prevention and mitigation, energy and resource problems, and environmental problems, it is important that the mutual relationships among science, technology, and society should be considered in the near future.

We also must deal with the relationships among these fields in education (see Fig. 5). Disaster prevention and environmental education are unlike other subjects taught in schools up to now in that they require a combination of the acquisition of knowledge, technical skills, and behavior. For example, safety education, including disaster prevention, is meaningful particularly because students must act based on their own estimations and judgments of particular conditions and circumstances. Moreover, in this type of learning, there is not necessarily a correct answer. Cases in which a teacher leading a class and experts in the field are unsure of an answer are common.

Regardless of the extent of knowledge that an individual accumulates, he or she cannot state for sure that knowledge alone will solve a problem, and often it does not. This leaves us with the increasingly perplexing question of what type of decisionmaking we should adopt, at all levels, from the individual to the national level.

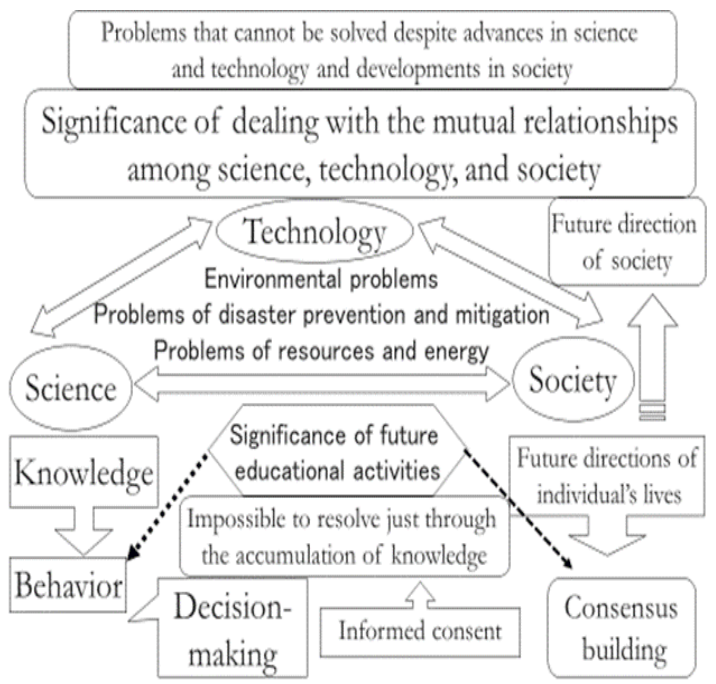

Figure 5. The mutual relationships among science, technology, and society 
The expression, "informed consent," is widely used in medical circles. It refers to a patient agreeing to a procedure after having listened to and been convinced by an explanation given by a specialist of that procedure's risks and possible benefits. Since the 2011 GEJET, there has been a wide-ranging debate regarding energy in Japan. Even when it comes to energy consumption, it is important to fully understand and be convinced of the advantages and risks involved in different ways to use energy.

In any case, it is safe say that, to this point, students have studied the topics covered in Japanese formal education with the assumption that there is an answer written down somewhere. However, from this point, students will need to search for and ask their own questions, and they must have an attitude of trying to find the answers themselves. Furthermore, students will be required to study about the ways that consensus can be built on a variety of topics regarding people and society.

\section{Conclusion}

It has been discussed the development of science education and environmental education in terms of the recent trends in Japanese education and regarding education directly related to natural disasters. The third session of the United Nations World Conference on Disaster Reduction was held in 2014, which was 20 years after the Great Hanshin-Awaji Earthquake, 50 years after the Niigata earthquake, 10 years after the Chuetsu Earthquake, and 10 years after the Sumatra earthquake. Furthermore, 7 years had passed since the 2011 GEJET, and, whereas attention was focused on the importance of disaster prevention education, landslides in Hiroshima Prefecture in August and the eruption of Mount Ontakesan in September caused many casualties. The year provided many opportunities to rethink the interrelationship between the natural environment and human activities and the connections between nature and humankind as well as those within society.

If environmental education, ESD, and disaster prevention education are ignored, a sustainable society cannot be hoped to build. The ESD perspective is that integrated efforts in numerous connected fields are required to achieve the construction of a sustainable society. In the sphere of learning, examples of these fields include international understanding, the environment, world heritage, and local cultural assets, and, in recent years, biodiversity and climate change can be added as well as disaster prevention to that list. These fields clearly demonstrate the strong connections between content and cultivation of the strengths required to achieve the goals of disaster prevention education.

Furthermore, safety education, including environmental education and disaster prevention education, presents important challenges to the future of Japan that must be carefully considered, including challenges from a human resources development perspective regarding teacher development and training.

It has been pointed out that many students do not understand how the knowledge they possess relates to their everyday lives or their futures. The challenge of education in Japan that demands cultivation of a "the zest for living" continues to be revealed from the results of comparative international assessments such as TIMSS and PISA. Moreover, since the 2011 GEJET, the desire has grown for new educational content and methods considering the international trends. Currently, there is demanding to move toward instruction that differs from that employed up until now and that advances educational development. Active learning, in which students actively engage in and advance their own studies, is one such method that has been recently gaining attention.

Last, the significance of what can be learned from the duality of the natural world, which provides the blessings of the natural environment as well as the terrible natural disasters, is something that education should engage with and something that Japan can communicate to the international community. Japan has been successful to this point at incorporating activities into education by which students learn from their experiences with nature. Educational activities that encourage reverence towards nature and a desire to preserve it not only help to improve academic achievement; they have value in their own right.

A variety of problems are rising on Japan's educational scene today, including bullying, truancy, difficulties raising achievement levels, and problems related to English and ICT education. As a result, it is difficult to maintain the attitude that solutions can be pursued to these problems while simultaneously looking to the future and preparing for disasters that could happen at any time. Nevertheless, efforts in disaster prevention education, which are linked to environmental education and ESD, can help us to find solutions to the challenges that are faced in education. In other words, disaster prevention education can be perceived as a tangible teaching method that can help to cultivate the skills that future generations will need.

\begin{tabular}{c|c|c|c|c|c}
\hline (C) Terrae Didat. & Campinas, SP & v.14 & n.3 & $313-319$ & jul./set. 2018 \\
\hline
\end{tabular}


Furthermore, schools alone cannot resolve the issues discussed above. Cooperation between entities, such as educational administrations and research institutions, is essential for the construction of a new educational system.

\section{Acknowledgements}

During the course of conducting this study, many prefectural board of education supervisors and school officials kindly provided me with information and materials. I would like to express my gratitude for their generosity. In addition, Grant-inAid for Scientific Research funding from Scientific Research (B) (representative: Fujioka Tatsuya, issue number 15H02915).

\section{References}

Fujioka T. 2006. Development of environmental education from the viewpoint of period of integrated study. Environmental Education, 16:32-38.
Fujioka T. 2011. Expectations for science education oriented towards the construction of a sustainable society. In: Fujioka T ed. 2011. Environmental education and integrated studies periods. Tokyo: Kyodosyuppan.

Fujioka T. 2015. Education for disaster risk reduction after the UNDESD (United Nations Decade of Education for Sustainable Development): From the viewpoint of construction of the model. Environmental Education in Japan, 24:40-47.

Fukushima Prefectural Board of Education. 2014. Disaster Prevention Educational Materials Nurturing a "the zest for living." Fukushima, Japan: Fukushima Prefectural Board of Education.

Ministry of Education, Culture, Sports, Science and Technology. 2012. Research report on the response of schools etc. to the Great East Japan Earthquake of 2011. Tokyo, 34: Ministry of Education, Culture, and Sports.

Ministry of Education, Culture, Sports, Science and Technology. 2013. Development of disaster prevention education nurturing a "the zest for living." Revised version; 1-233, Tokyo, Japan: Ministry of Education, Culture, Sports, Science and Technology..

Terada T. 1934. Natural disaster and national defence. In: Toyotaka K. ed. Terada Torahiko essay collection; fifth Volume, Iwanami Shoten. 305. 